\title{
Exploration of Reform and Practice of Classroom Teaching of High Frequency Electronic Circuits Based on Chaoxing Learning App
}

\author{
Li-qin $\mathrm{GaO}^{\mathrm{a}}$, Wu-sheng $\mathrm{Ji}^{\mathrm{b}}{ }^{\mathrm{*}}$, and Wei-wei Zhou ${ }^{\mathrm{c}}$ \\ ${ }^{1}$ School of Electronic Engineering, Tianjin University of Technology and Education, \\ Tianjin, 300222, China \\ a2396930041@qq.com, bwshji1326@sohu.com, ${ }^{c} 1430253469 @ q q . c o m$
}

\begin{abstract}
High Frequency Electronic Circuit is an important technical foundation course for electronic majors. It is hard to teach and learn in this course for a long time. In order to solve these problems, we propose a method of taking the intelligent mobile phone as a carrier and the Chaoxing Learning App as the platform to directly use the mobile terminal for lightweight course teaching, which can realize the functions of signing, interacting, investigating, obtaining resources and so on. The purpose of this method is to combine mobile teaching with classroom teaching to improve the teaching quality. The participation of Chaoxing Learning App can broaden the unidirectional teaching and learning restrictions in traditional classroom teaching. It can also transform the academic inculcation education into applied interactive learning, which is an effective way to improve teaching level and learning efficiency. Besides, we have pointed out some problems existing in the current development and the direction of further research and exploration.
\end{abstract}

Keywords-Chaoxing Learning App; High-frequency electronic circuits curriculum; Smart phone; Interactive teaching; Lightweight

\section{The Basis Of ThE TEACHING REFORM OF HigH FREQUENCY ELECTRONIC CIRCUIT}

A. The current teaching status of High-frequency Electronic Circuit and the feasibility analysis of mobile client application to the course teaching

High-frequency Electronic Circuits (hereinafter referred to as the "High Frequency") is the important technical basic course of electronic and information profession. It has strong theory, engineering and practicality. It is also rich in content and widely used, and is one of the most difficult courses to learn and teach in this professional curriculum. For beginners, because the traditional High Frequency course is stiff, boring in classroom teaching content, lack of experimental interest, it is a urgent need to adopt a more novel teaching method to improve the teaching effect.
With the rapid development of communication technology, college students' love for smart devices is becoming more and more strong, especially the reliance on mobile phone. Indulging in class mobile phone has become an important factor affecting the teaching effect. How to use the mobile phone to work for us, make the mobile phone to become the auxiliary teaching tool, and well-deserved entry into the classroom? It has become an important topic in our classroom teaching reform. In March 2012, the Ministry of Education issued "a development plan of Education informatization in ten years (2011-2020)". It put forward to promote the depth of the integration of information technology and education and establish a government involvement in resource sharing mechanism to encourage enterprises to develop digital education resources platform to provide services for learners. Mobile education can promote the development of the national construction of learning society. The future will become an important part of social development. On March 5, 2015, Premier Keqiang Li put forward the "Internet plus" action plan for the first time in his government work report during the Two Sessions. In 2016, China's three basic telecom enterprises entered the era of " $4 \mathrm{G}+$ " together. Nowadays, the popularity of mobile terminals and the optimization of the network make online education gradually focus on mobile terminals. At the same time, many enterprises also begin to focus on the App model. The number of Education Apps is now more than 70,000 , second only to games in the app store, and accounting for over 10\%/1/. Among them, the Chaoxing Learning App launched by Chaoxing Company is widely used, which is a real-time interactive teaching and learning platform designed and developed based on mobile Internet technology and mobile terminal equipment and suitable for Android and IOS system. Therefore, at home, there is the fertile soil suitable for mobile teaching clients to traditional teaching, which makes mobile teaching assistant walk into the classroom, accelerating the effective integration of teaching App and the traditional classroom. As shown in figure 1: 


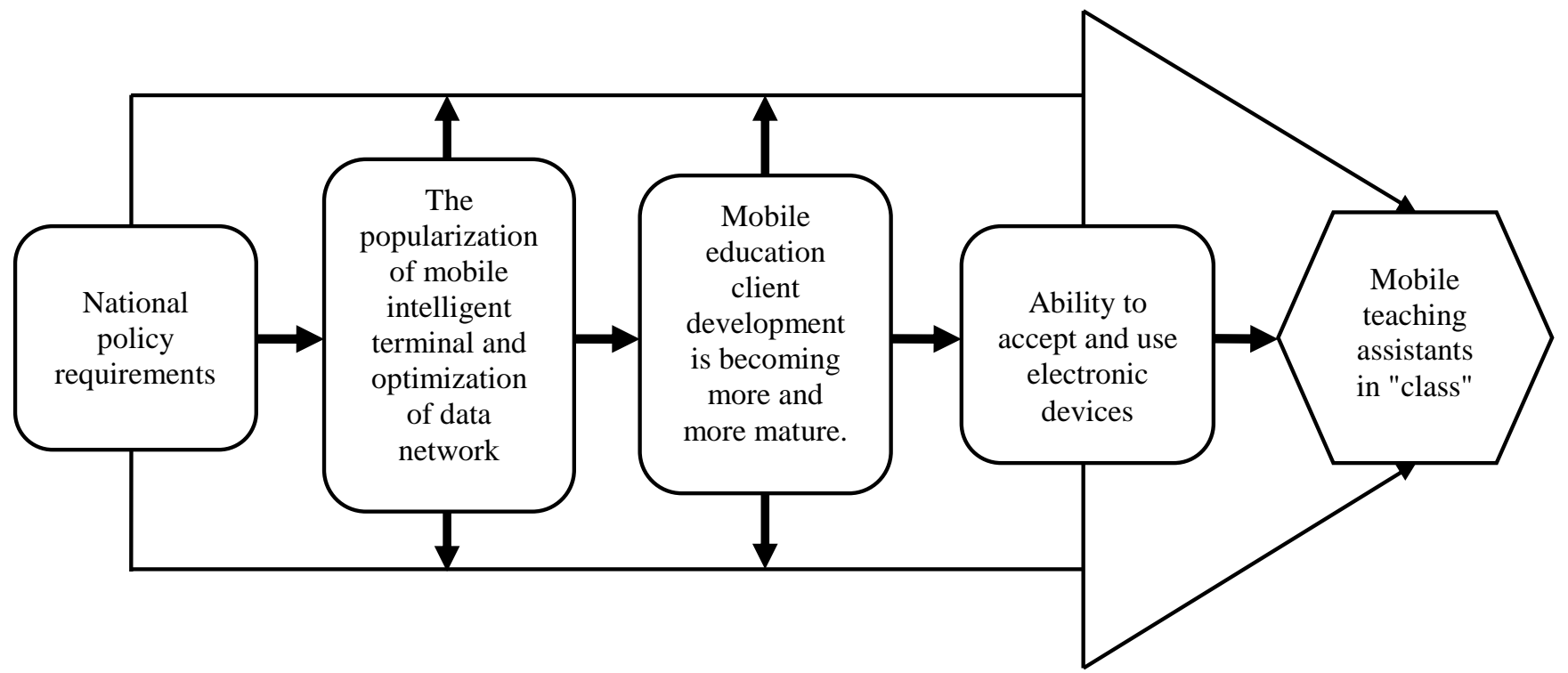

Fig. 1. Main factors driving the development of mobile teaching clients in China

\section{B. Status quo of Chaoxing Learning App platform construction}

Chaoxing Learning App is an early professional mobile learning App in China. It adopts mobile cloud technology, which can be used in mobile phones, laptops and other terminals, and has a PC version. The platform, including teachers and students' aspect, presents a perfect link of teaching and learning. Based on the mobile interconnection environment, it realizes the real-time interaction, release resources and assignment tasks between teachers and students. It has perfect incentive and evaluation system, which can effectively stimulate students' interest in autonomous learning on mobile devices. Meanwhile, it can record students' learning behaviors in real time, realize the process assessment and final assessment of students, and provide high quality teaching research data for teachers. Chaoxing Learning App defines the new mode of teaching interaction in the intelligent Internet environment. As a timely feedback interactive teaching tool, it can realize easy and interesting interactive teaching. In this paper, we intend to use Chaoxing Learning App to the High Frequency Curriculum to improve its teaching efficiency.

\section{INTERACTIVE TEACHING PROCESS}

Based on Chaoxing Learning platform, it can construct a system of High Frequency interactive teaching, guide the student through each module task for learning and thinking, and promote the depth of the online teaching mode. This way can not only arouse the enthusiasm of students in learning to explore and initiative, cultivate students' ability to solve practical problems using the basic knowledge and theory of the circuit, and own the design, debugging and other basic skills. In the course of teaching implementation, we should avoid the simple superposition of online learning and physical classroom, focusing only on formal "integration", while ignoring the "fusion" of connotation. To avoid teaching becoming a mere formality, the teachers should make good use of Chaoxing Learning App; and it optimizes the combination of various teaching resources to make teaching resources, teaching situations and teaching methods better serve the whole teaching process. As shown in figure 2: 


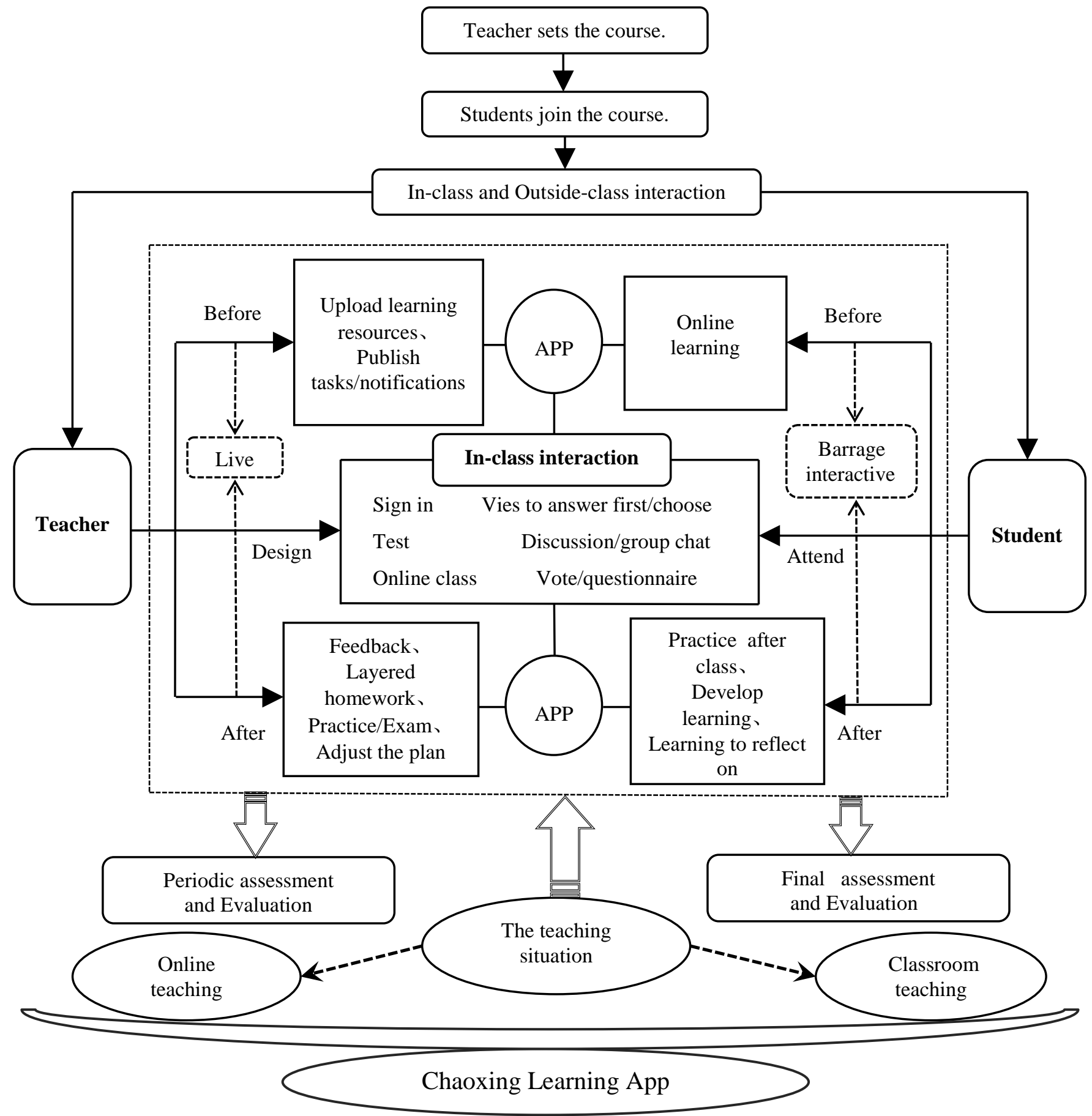

Fig. 2. Application mode about Chaoxing Learning App applied to the teaching implementation

By using the smart phone as the carrier and Chaoxing Learning App as the platform, we can directly use the mobile terminal for the lightweight High Frequency course teaching application, which implements many functions, such as checkin, interaction, investigation, resource acquisition, etc. The aim is to combine mobile teaching with classroom teaching. Before the beginning of class teaching, the teacher will set a good course on the learning App, and fill in the course name, class and information of the school according to the instructions.
After the setting is completed, the students are informed by QQ, WeChat and other information ways to use the invitation code to join the course. With the learning platform, we can achieve resource sharing, learning interaction, teaching guidance and management. Teachers design and build a curriculum platform to guide students to learn independently, so that they can fully reflect the active position of students in active exploration and innovation. At the same time, we, through the network interactive teaching mode of exploration, can reform the 
traditional cramming teaching, greatly improve teaching efficiency and effect, and also can further improve students' subjective initiative in the teaching.

\section{A. Pre-class learning based on the guidance task list}

This link should take full account of the difficulty of classroom teaching and teaching objectives, and combine with a large amount of teaching resources to design in a targeted way.

Before the class, teachers post new lesson requests, notifications, learning resources (including documents, photos, videos, notes) and tutorials in the course they have set. Students receive the learning notice, in accordance with the requirements of the learning task list to complete the task of pre-class learning. In addition, for what is difficult to master in the new course, teachers communicate with each other in advance in the form of "live broadcast" as needed. Teachers and students can shorten the distance between each other through the "barrage interaction" and easily realize interactive teaching. At the same time, using this more popular method of the moment, we can also attract students' attention in a greater extent and enhance their interest in learning

\section{B. Interactive teaching in the class based on Chaoxing learning App}

\section{1) Sign in}

The teacher in class through the "normal", "gesture" and "qr code" in a variety of ways, such as easily complete sign in work, to supervise and urge students to class on time, and as an effective basis for attendance statistics. Compared with the long time to survey attendance and easy to lost for attendance data in the traditional class, the Sign-in function saves a lot of trouble. And it can greatly reduce the roll call time. Then system function of the automatic statistics and management also can ensure the student attendance information fairness and integrity.

\section{2) Discussion/Group Chat}

In the course of teaching, teachers should initiate a topic according to the curriculum. The students expressed their opinions on the topic and asked for the teacher's opinions and answers. The teacher looked at the students' answers and gave them feedback. For blind area of study, students, in the Discussion/Group chat area, left contents in the form of text, images and solutions to seek for the aid of classmates and teachers. They can discuss each other anytime and anywhere, solve doubts in the heart, and deepen the mastery of knowledge points. According to the satisfaction of the answer, the participants can thumb up and comment on each other, achieving a diversified evaluation method, which greatly stimulates the students' learning desire. At the same time, the discussion topics are visible to other people in the same field, thus it can broaden the scope of the discussion and facilitate indepth communication.

\section{3) Task}

Teachers assign class tasks through pictures, audio, video, documents, etc, and set up the deadline for tasks. Students complete them in the form of individuals or groups. The teacher can go through the solutions according to the answers; and they also can designate the students who are not well done to resubmit.

\section{4) Vote/Questionnaire}

Through the part, teachers can survey students' learning attitudes, learning experiences and the degrees of mastery of the course knowledge, so that teachers improve the teaching design and teaching methods, and implement of targeted teaching. In the course of High Frequency teaching, teachers design questionnaires according to the class situation, and release them through the Voting/Questionnaire function. Teachers can understand students' learning effect, learning attitude and learning experience in a timely manner, and the system can make statistical investigation results and simplify the research process.

\section{5) Choose/Vies to Answer First}

In class teaching, students are randomly selected to answer questions, making class questions mysterious and interesting. When teachers set link of Vies to Answer First in the course of teaching, students spontaneously answer the teacher's question. At the same time, the teacher, according to students' answer, will give corresponding scores as a bonus to enhance the classroom activity and stimulate the students' participation consciousness and competitive consciousness.

\section{After-class testing, feedback and promotion based on Chaoxing learning App}

As the detection and consolidation of new knowledge, layered assignment and test are very important in teaching. The system provides powerful job and test functions. Teachers design the test questions according to the knowledge target, or directly use the finished questions. It is suitable for pre-class preview effect test, periodic test and final exam. When the test is carried out, the system completes the examination management by itself and realizes the whole process assessment.

\section{Statistics and analysis of learning situation}

\section{1) Statistics of learning situation}

After the teaching, teachers can query the participation and completion of students in the teaching activities, including resource views, chapter test points, video watching, attendance rate, class and assignment/test, and so on.

\section{2) Statistical results}

After the students completed the test, the teacher checked the students' answer questions by themselves. In the Chaoxing Learning App, the proportion of students in each score segment is statistically analyzed by means of pie chart. For the test results of the students, the teacher can see the correct rate of the answer directly, so as to determine the error prone and master the better knowledge points, and then adjust the follow-up course plan. 


\section{CONCLUSION}

\section{A. Analysis of teaching effect of mobile APP}

Mobile teaching mode is an extension of the traditional classroom teaching rather than subversion. Compared to the normal online education, In the course of teaching, the participation of mobile platform enables effective communication and feedback between teachers and students and students and students, and avoids the monotony and tiredness of simple online learning. Using online learning resources, students can easily preview the High Frequency courses. According to the students' preview test results, the teacher will give an emphasis discussion in class. Meanwhile, teachers can discuss, test and investigate the content of the learning in order to master the knowledge of students in a timely manner. Then, they can adjust and improve the teaching plan according to the evaluation and analysis of learning record, attendance and class performance. Mobile teaching assistants can broaden the one-way transmission and limitation of learning in traditional classroom teaching, so as to transform the academic "education" into the applied "interactive learning". The interaction between before and during class can enhance the effectiveness and efficiency of classroom teaching, which is an effective means to improve teaching quality and teaching efficiency.

\section{B. Existing problems and the direction of efforts}

If you want the teacher to give up the teaching method of the teacher's unilateral teaching and the student sponge type absorption, the biggest problem at the moment is how to get students to get used to autonomous learning. Most students receive passive education in education system, and there is a general lack of impetus to transfer from tradition education to online. And the national tradition of passive learning determines that the further development of mobile teaching needs a long process. Secondly, the unsound construction of online education platform environment is an important reason for the sluggish development of mobile teaching clients. Chaoxing Learning App is a new mobile cloud teaching tool, and many functions need to be perfected. In teaching practice, it is often because the network is not smooth and the students' check-ins, resources and feedback are delayed. There are limited courses available on the platform. For many school courses, there is no corresponding bibliography on it, which reduces the scope of reference learning materials, thus affecting the learning efficiency. Therefore, we should focus on improving the efficiency of classroom network operation, and further strengthen the construction and resource service of Chaoxing Learnig platform. In the design course learning activities, in order to improve the students' participation and enthusiasm of autonomous learning, we should put special emphasis on the diversity of learning tasks, management strategies and the design of activity regulations. Then we also need to carry out in-depth practical research. This is what we need to study and explore further.

\section{ACKNOWLEDGEMENT}

The work is supported by the general project of the research on the teaching reform and quality construction of Tianjin University of Technology and Education in 2015 (JGY201527).

\section{REFERENCES}

[1] Chen Wang, Nan Liu, Internet + education --- education revolution in the mobile Internet era, China Economic Publishing House , pp. 1-25, 2015. (In Chinese)

[2] Chenglin Ye, Fuyin Xu., Mobile learning and its theoretical basis, Open Education Research, vol. 3(10), pp.23-26, 2004. (In Chinese)

[3] Jingjing $\mathrm{Xu}$, Huan Zhang. Reform and exploration of the teaching of mobile terminal application technology, Success Education, vol.11, pp. 15-16, 2011. (In Chinese)

[4] Lingyan Yuan, The reform of teaching mode based on the Internet --. the application of Mosoteach in the teaching of Electric Technology Foundation curriculum, Oriental Education, vol. 9, pp.204-205, 2015. (In Chinese)

[5] Aixia Zhao, Luping Zuo, Mobile live + education mode, TV Research, Vol. 5, pp.62-64, 2017. (In Chinese)

[6] Jing Xie, Research and exploration on the teaching reform of High Frequency Electronic Circuits, Education Teaching Forum, vol. 5, pp.62-63, 2016. (In Chinese)

[7] Yinglian Zhou, Exploration and practice of the course teaching reform of "High-frequency Electronic Circuit" , Education Teaching Forum vol. 7, pp. 126-127, 2016. (In Chinese)

[8] Dan Liu, Weixing Hu, Analysis of the Development and Application of Mobile Education APP, e-Education Research , vol. 8, pp. 47-52, 2016. (In Chinese)

[9] Tangsen Huang, Intelligent mobile teaching in Android application development foundation course reform and practice, Information Technology \& Informatization, vol. 8, pp.67-69, 2016. (In Chinese)

[10] Yin Zhang, Yanmin Niu, Application of mobile teaching platform in higher education teaching, Software Guide, vol. 3, pp.23-24, 2017. (In Chinese)

[11] Wen Yang, Shu Xiang, Research on hybrid teaching based on mobile terminal, Literature Education, vol. 10, pp. 140-142, 2017. (In Chinese) 